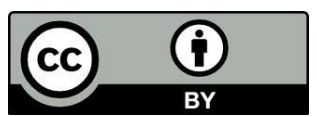

\title{
GÊNERO E DISCURSO RELIGIOSO
}

\author{
Gender and religious speech
}

RESUMO: Este artigo relaciona gênero e modelos de Deus, mostrando como o tráfico de seres humanos desvela situações de dominação, escravização e discriminação que estão presentes na sociedade atual. Denuncia, ao mesmo tempo, a sutil existência de uma cultura patriarcal, dualista e hierárquica que se sustenta através do discurso religioso. Usando o referencial teórico de gênero faz uma crítica a esta cultura e apresenta algumas raízes bíblicas da teologia da Sophia como um caminho que leva á vida digna e abundante para todas as pessoas.

Palavras-chave: Gênero. Religião. Mulher. Cidadania. Justiça.

ABSTRACT: This article relates gender, and models of God, showing how human trafficking reveals situations of domination, enslavement and discrimination that are present in society today. Denounces, while the subtle existence of a patriarchal, dualistic and hierarchical culture that is sustained through religious discourse. Using the theoretical framework of gender makes a critique of this culture and presents some biblical roots of the theology of Sophia as a path that leads to the dignified and abundant life for all people.

Keywords: Gender. Religion. Woman. Citizenship. Justice. 


\section{Introdução}

A questão de gênero não somente desperta para as históricas construções que constituem nosso modo de viver como mulheres e homens, mas torna-se também uma provocação e um convite para rever os modelos de Deus que são interiorizados automaticamente, através da ideologia de dominação subjacente aos discursos religiosos. Segundo Ivone Gebara, a questão de gênero "nos convida a rever nossos modelos de construção teórica sobre Deus e a examinar as implicações culturais e sociais na vida das mulheres e dos homens de um determinado contexto" (GEBARA, 2000, p. 109).

E o contexto atual que exige a desconstrução dos discursos religiosos discriminadores e inferiorizadores é o da crescente violência contra mulheres, crianças, jovens, negros, indígenas, pessoas que fizeram caminhos diferentes, que não estão dentro dos padrões tradicionais. Outro aspecto atual que exige análise crítica de gênero é o aquecimento global e toda a questão do meio ambiente, provocando trágicos desastres ecológicos, que divulgados de maneira sensacionalista não levam a população a perceber que é hora de mudar.

No contexto em que vivemos é tão grande e diversificado o avanço da ciência e da tecnologia que imaginamos estar vivenciando um processo irreversível de crescimento e superação da miséria, da ignorância, das doenças, da violência e da dor. Pensamos que os novos conhecimentos científicos são capazes de garantir a vida do planeta e dos seres vivos que nele habitam. No entanto, convivemos com as formas mais sutis de violência e de escravidão de seres humanos.

\section{Tráfico de seres humanos}

Segundo o Pe. Alfredo J. Gonçalves, “da mesma forma que a escravidão clássica, tanto no mundo antigo, como no mundo medieval e moderno, a prática de mercantilizar a vida humana e a exploração de sua força de trabalho costuma render lucros fabulosos para as "máfias" ou o "crime organizado" de todos os tempos e lugares" (GONÇALVES, 2013, p. 54). Uma grande maioria dessas pessoas traficadas é formada por jovens que sonham trabalhar e fazer fortuna em outros países e nem se dão conta de que estão entrando em um sistema ilegal de migração de trabalhadores, onde, além do 
trabalho escravo na prostituição, os corpos humanos são utilizados para a venda de órgãos e pornografia infantil. A ONU afirma que, globalmente, 4,5 milhões de pessoas são vítimas de tráfico para a exploração sexual. Dados recentes da UNODC ${ }^{1} / 2012$ mostram que $76 \%$ das vítimas do tráfico de seres humanos são do sexo feminino e que $26 \%$ são crianças e adolescentes. Esta é uma das atividades ilícitas mais lucrativas na atualidade, rendendo cerca de 32 Bilhões de dólares por ano. Uma situação de violência perversa e constante, que cresce cada dia mais, sendo atualmente a terceira maior fonte de lucros em um mundo globalizado, onde a migração tornou-se uma alternativa de sobrevivência.

E este tipo de violência, presente em nosso cotidiano, passa a ser visto com certa naturalidade. Por um lado, respeita-se a liberdade das pessoas que desejam arriscar-se a ir a outros países em busca de melhores salários. Por outro, estas máfias que comercializam seres humanos estão muito bem articuladas e quando se percebe ou se toma conhecimento da situação na qual se envolveu uma pessoa conhecida, a experiência de impotência leva familiares ou vizinhos a dizerem: não podemos fazer nada!

Porém, há algo muito grave e sutil por trás desta prática criminosa e da impotência que experimentamos: "há uma cultura dualista que ainda nos habita, muito embora de forma diferente do passado" (GEBARA, 2013, p. 107). Esta cultura dualista é comunicada através do discurso religioso. Nossa espiritualidade está marcada pela filosofia grega, que na verdade era a vivência e a reflexão de uma elite masculina com sua visão dualista do mundo e do ser humano. Por sua própria origem, a filosofia grega excluía pessoas pobres e mulheres consideradas seres inferiores e incapazes de produzir conhecimento. A teologia cristã transformou o pensamento de alguns filósofos gregos como Platão e Aristóteles, em um padrão básico para a sua reflexão sobre Deus, dando continuidade a um discurso teológico elitista capaz de manter um conceito patriarcal e hierarquizado em relação a todos os corpos.

Nessa cultura, deu-se uma forte carga simbólica aos corpos das mulheres. "Os valores que as mulheres representam e encarnam são valores simbólicos secundários e não privilegiados pelo sistema patriarcal que os fomenta e ao mesmo tempo desvaloriza (Isto acontece até mesmo com valores como a ternura e a capacidade de sofrer). Estas

${ }^{1}$ A UNODC é o escritório das Nações Unidas sobre Drogas e crimes. 
representações simbólicas sustentam e legitimam o próprio sistema patriarcal que as alimenta" (GARCÍA, 2011, p. 61).

Dessa maneira, "os corpos religiosos estão prisioneiros ou são prisioneiros voluntários de um sistema que continua legitimando a superioridade de uns em relação aos outros. E este sistema tem sua dose de responsabilidade na manutenção de estereótipos, de formas de socialização e dominação além de permitir que as mulheres sejam ainda consideradas cidadãs de segunda classe. Tudo isso tem consequências que precisam ser avaliadas no presente momento de nossa história" (GEBARA, 2013, p. 106).

\section{O referencial teórico de gênero}

Delir Brunelli contribui para a compreensão desta cultura dualista e discriminadora, afirmando que "gênero indica os traços típicos, os papéis que culturalmente foram atribuídos a homens e mulheres, estabelecendo um determinado padrão nas relações sociais" (BRUNELLI, 201, p. 9). Estes padrões são gerados a partir da maneira como um grupo social se compreende e exerce o seu poder. Eles mostram os tabus e as dificuldades de integração da sexualidade e da afetividade por um determinado grupo social. Mitos e tabus servem para justificar a dominação e esconder o medo. Estes mitos e tabus estão presentes também na Bíblia. São um reflexo da sociedade patriarcal dentro da qual a Bíblia foi escrita, já que as antigas religiões nasceram dentro deste tipo de sociedade. Mitos, símbolos e tabus tecem um imaginário que induz à legitimação do sujeito hegemônico masculino, legitimando a violência contra a mulher e colocando todas as demais criaturas, inclusive a natureza, na categoria de objeto.

Raquel Carmen Riquelme Martinez afirma que "a possibilidade de uma mudança nos discursos religiosos teológicos androcêntricos, que vise estabelecer a igualdade entre os gêneros feminino e masculino, ajudaria na superação da violência contra a mulher assim como na superação da atitude submissa e passiva à qual ela tem sido vinculada, proporcionando à mulher a superação de ser apenas objeto para ser sujeito de sua própria história” (MARTINEZ, 2003, p. 88). 
Mas, não é somente o cristianismo que se originou dentro de uma cultura patriarcal. Também religiões antigas como o hinduísmo, o confucionismo, o judaísmo e o islamismo nasceram em sociedades patriarcais, que vão mudando sua linguagem, atualizando seus discursos e, no entanto, não mudam seus dualismos hierárquicos. Como discernir a experiência de fé que impregnam estas religiões, quando estão carregadas de preconceitos, prescrições e ideologias próprias do contexto no qual foram vivenciadas? Como perceber os condicionamentos culturais de uma sociedade patriarcal expressos na sua linguagem sobre Deus? Como descobrir a influência do sistema patriarcal na nossa cultura e, consequentemente, em nossa espiritualidade? Estes questionamentos apontam para o referencial teórico de gênero como uma ferramenta de análise e desconstrução dos poderes dominadores e excludentes que se justificam através do imaginário religioso patriarcal.

\section{O QUE É UMA RELIGIÃO PATRIARCAL?}

Uma religião patriarcal caracteriza-se por sua estrutura piramidal, na qual os homens possuem o poder de posse e de decisão sobre mulheres, filhos/filhas, escravos/escravas. Elisabeth Schüssler Fiorenza denomina este poder como um poder kyriarcal (FIOREZA, 1992), e explica o seu significado mais amplo: "O poder kyriarcal opera não somente junto com o eixo de gênero, mas também com os de raça, classe, cultura, e religião. Estes eixos de poder estruturam os sistemas mais generalizados de dominação, numa matriz (ou melhor, "patriz") - numa espécie de modismo, ou numa tendência a acolher o que é mais badalado - entrelaçando os sistemas de opressão. Esta "política de dominação refere-se ao terreno ideológico que eles compartilham, que é uma crença nas noções de dominação e de superior e inferior.... (FIORENZA, 2002). Esta aclaração de Fiorenza deixa transparecer a presença de uma cultura de matriz religiosa, com raízes patriarcalistas, em sistemas atuais de dominação e exploração.

Segundo Tânia Mara Vieira Sampaio, "a concepção das relações sociais de gênero se apresentam como um novo paradigma, capaz não somente de visibilizar mulheres e/ou grupos oprimidos, mas também de iluminar as descobertas sobre a estrutura das opressões e dos jogos de poder que organizam discursos normativos e estabelecem controles sociais. Mais que um encontro entre histórias de vida, essa 
maneira de ler a realidade quer demarcar uma nova trajetória dos paradigmas de construção dos conhecimentos e de decodificação dos discursos" (SAMPAIO, 2003, p. $82)$.

Nos últimos 70 anos, o patriarcado tem sido compreendido e explicado como um sistema de exploração dominação baseado na relação de poder entre macho e fêmea. Algumas teorias feministas sustentam que esta desigualdade de gênero é à base de toda dominação e exploração que permeia a humanidade, gerando desigualdades e exclusões econômicas, de raça/etnia, religiões e de gerações. Esta visão vem sendo constantemente aprofundada por Fiorenza:

O sistema patriarcal é definido como dominação do homem e exclusão da mulher da política, cultura, história e religião. A dominação patriarcal tem sido onipresente, atravessando totalmente o tempo e o espaço. As mulheres não são somente os objetos e vítimas das regras masculinas, mas também agentes complacentes na medida em que elas têm sacrificado seu próprio interesse em prol do desejo de viver para o bem estar dos homens $(2002, \mathrm{~s} / \mathrm{p})$.

\section{IMAGINÁRIO ANDROCÊNTRICO DE DEUS}

Para entender melhor a sutileza desses condicionamentos existenciais, temos que examinar com mais acuidade a maneira como a teologia cristã, de um modo geral, mantém engessado o discurso religioso, insistindo nas metáforas patriarcais e triunfalistas para falar sobre Deus. O problema de tal discurso reside, em primeiro lugar, na ausência de uma contraparte feminina em sua concepção da divindade, pois, segundo José Severino Croatto "construímos uma imagem irreal de Deus, que não tem equivalente em nossa experiência cotidiana. Com isso, perde seus contornos a linguagem simbólica que projeta na divindade o que é parte de nossa experiência" (CROATTO, 2001, p. 28).

Outro problema é que as imagens de Deus que tal discurso privilegia justificam e mantêm a dominação e a exclusão de leigos, especialmente das mulheres, das estruturas das igrejas cristãs. O que é, ainda, mais trágico é que as estruturas de dominação e opressão que se encontram em textos bíblicos e, sobretudo, em suas interpretações têm influência direta sobre a vida das mulheres. Por isso, Elisabeth Schüssler Fiorenza 
afirma que "devemos adotar uma 'postura feminista' ao lado das mulheres que lutam no lugar mais baixo da pirâmide kyriarcal de dominação e exploração, porque suas lutas nos revelam tanto a base da desumanizadora opressão que ameaça a toda mulher como o poder da Divina Sabedoria, que já está no meio de nós” (FIORENZA, p. 125).

Para M. O’Brien “uma abordagem feminista ou liberacionista do texto bíblico, quando aplicada e avaliada criticamente, permite ver coisas que podem ter sido obscurecidas por outras leituras. Uma vez que alguém toma consciência do preconceito presente na Bíblia, isso pode ter um impacto sobre a compreensão que essa pessoa tem da autoridade da Bíblia e sobre como ela transmite a experiência de Deus. Apesar disso, quando tratado criticamente, este preconceito pode ser visto numa luz menos negativa" (2001, p. 77). O’Brien lembra, também, que "um estudo crítico dos textos bíblicos considera os autores como teólogos criativos e seus textos como discursos teológicos e não como registros" (2001, p. 71).

Sem ter acesso a esta percepção crítica, "os seres humanos introjetaram uma imaginário androcêntrico de Deus que se concretiza na sua vida social e pessoal. Este imaginário é utilizado para sustentar ou criticar certas estruturas, valores e formas de ação, pois há uma relação interdependente entre um sistema simbólico religioso e as disposições e motivações que ele estabelece" (MARTINEZ, 2003, p. 88). A imagem de um Deus androcêntrico torna-se o eixo de uma religião antropocêntrica, de um sistema teológico hierárquico e excludente no qual a cultura cristã ocidental se apoia, se estrutura e se sustenta.

\section{Imagem feminina da divindade}

Nossa formação na família, na escola, nas igrejas foi condicionada por modelos masculinos de Deus, transmitidos através da Bíblia e das tradições eclesiais. Neste sentido, Fiorenza nos adverte de que "os textos bíblicos kyriarcais contam história e constroem mundos sociais e universos simbólicos que mitologizam, invertem, absolutizam e idealizam diferenças e desse modo distorcem ou marginalizam a presença histórica dos "Outros" (FIORENZA, 2009, p. 166). Nesse sentido, não somente mulheres bíblicas foram esquecidas ou difamadas na história da interpretação dos textos, como, por exemplo, a figura de Maria Madalena (SEBASTINI, 1995). Também 
ficou no esquecimento a encantadora imagem da Sophia, artista do universo, que se delicia com os seres humanos.

No poema de Provérbios 8, 22-31, a Sophia é apresentada inicialmente como pré-existente à criação toda para, em seguida, ser colocada ao lado de Javé, como artista do universo. Este é um poema impressionate, onde vemos a sabedoria ir crescendo até alcançar aspectos de Deusa. Nos versos finais deste poema, a Sophia proclama bem aventuradas todas as pessoas que a procuram, velando à porta de sua casa $(\operatorname{Pr} 8,34)$, pois "quem a encontra, encontra a vida" (v.35). Nesta conclusão, está claramente expressa a sua face divina, já que a Sophia está se apresentando como doadora de vida, ou como princípio de vida ${ }^{2}$. Já em Pr 9,1-6, a Sophia possui os traços de uma uma mulher competente, que constrói sua casa e prepara com atenção um banquete, enviando suas criadas para fazer convites a todas as pessoas, a partir dos pontos altos da cidade. Chama a atenção o fato do número sete aparecer repetido neste pequeno texto, dandolhe um sentido de plenitude. A casa que a sabedoria mulher constrói tem sete colunas e sete são os verbos que descrevem sua ação. Tanto o plural majestático ${ }^{3}$ com o qual é iniciado este poema, como o número sete são recursos utilizados pelo poeta para demonstrar sua grandeza, que está relacionada à sua postura ética. Uma postura que transparece na escolha de seus principais convidados: os "ingênuos" e aqueles que estão sem sentido para viver, "sem coração" (v.4-5). Esta opção demonstra que a sabedoria mulher tem, neste poema, uma postura inclusiva, escolhendo gente sem conhecimento (petayim) e sem um sentido para a viver (hasar leb). Pessoas escravizadas, humilhadas, discriminadas são suas convidados especiais.

Ao fazer seu convite, a Sophia usa os imperativos "venham!", “comam!" e “bebam!” (v.5). Tal convite expressa claramente que a participação em sua comida, gratuitamente oferecida, exige uma mudança de postura: "deixai a ingenuidade e vivereis!" (v.6). A Sophia se aproxima de todas as pessoas que a acolhe e aceitam o convite para compartilhar do seu banquete, contanto que deixem a ingenuidade e busquem o caminho da vida. Aqui, é interessante observar que o caminho da vida leva a

2 Os poemas de Provérbios 8,3-36 estão na primeira pessoa do singular. É uma autoapresentação ou revelação da Sophia.

${ }^{3}$ Hokmot em hebraico é um plural e significa Sabedorias. No entanto, todos os verbos, adjetivos e pronomes relacionados com este termo que significa (Hokmah/Sophia) estão no singular. Este pode ser um recurso literário para indicar sua transcendência. 
ela mesma, pois isto está claramente expresso, através do convite imperativo: "venham!" Desta maneira, transparece um traço divino no rosto da Sophia de Pr 9,1-6. Descobrimos, ainda, que este texto foi inspirado nas ações das mulheres judias de um período mais recente do pósexílio (Século 4 AEC) quando, cheias de força e dignidade, elas assumiram funções importantes para dar continuidades à história do seu povo. Estas características da mulher criativa e competende da vida real transparecem no texto de $\operatorname{Pr}$ 9,1-6 e estão maravilhosamente descritas no capítulo 31 de Provérbios (LOPES, 2007, p. 195).

Mas, foi por tanto tempo oculta esta imagem feminina de Deus que se faz necessário apresentá-la melhor. Para isso, vamos observar que na introdução do livro dos Provérbios (1,2-3), afirma-se que a sabedoria é imprescindível para o conhecimento da justiça e do direito. Em seu discurso poético, transmitido em primeira pessoa, a Sophia afirma que possui os mesmos dons do messias esperado e que sua missão é promover a justiça. Desta maneira, encontramos uma referência a Is 11,1-9 em Pr 8,1121, onde A Sophia se apresenta com as qualidades messiânicas e proféticas para estabelecer a justiça e restabelecer a harmonia do universo. Este compromisso religioso de estabelecer e praticar a justiça é um dos aspectos mais importantes da identidade do povo bíblico. Ele mantém viva a memória da libertação do Egito e da dependência tributária aos reis cananeus. O compromisso histórico/religioso de estabelecer a justiça e de cuidar da harmonia do universo possibilitou a aceitação da imagem ou símbolo da Sophia, com suas múltiplas faces que retratam a mulher da vida real, as Deusas cuidadoras da vida e o próprio Javé. Penso que foi o tema da justiça que possibilitou a formulação de um messianismo feminino neste belíssimo poema ( $\operatorname{Pr} 8,11-21)$.

\section{Considerações finais}

Concluindo, posso afirmar que nosso tempo exige uma grande mudança cultural, social e religiosa. A partir da casa interiorana de Judá, a mulher resgata a solidariedade tribal, transmite ensinamentos importantes para a identidade do povo, administra sua própria casa com autonomia e competência, expandindo sua atuação ao espaço público. Esta mudança possibilitou uma nova visão da mulher e estabeleceu relações novas entre as pessoas e com a divindade. A nova visão provoca uma grande mudança no sistema 
simbólico de Israel, possibilitando a representação de seu Deus através do símbolo da Sophia. Este símbolo origina-se não somente da nova visão da mulher, mas da memória de antigas Deusas e de mulheres corajosas e sábias que ajudaram na construção da história do povo bíblico.

Parece-me importante insistir também que há nos poemas da sabedoria personificada, em Provérbios, uma indicação da dependência mútua entre os sistemas sociais e os sistemas cósmicos ( $\operatorname{Pr} 8$ ). Esta relação torna-se visível e até mesmo paupável em nossos dias, com o crescente empobrecimento dos povos e o esgotamento das forças vitais do planeta terra. Por isso, como afirma Leonardo Boff, "mais do que nunca, precisamos ter sabedoria. Sabedoria para captar as transformações imprescindíveis. Sabedoria para definir a direção certa. Sabedoria para projetar o sonho que nos guiará. Sabedoria, enfim, para priorizar as ações concertadas que vão traduzir este sonho em realidade". (1998, p. s/p).

\section{Referenciais}

BOFF, Leonardo. $O$ despertar da águia. O dia-bólico e o sim-bólico na construção da realidade. Petrópolis: Vozes, 1998.

BRUNELLI, Delir. O que é mesmo gênero? Em Sonhos e sementes. Rio de Janeiro: Cadernos da CRB, n. 30, 2001, p.9-16.

CROATTO, José Severino. A sexualidade da divindade. Reflexões sobre a linguagem acerca de Deus. Revista de Interpretação Bíblica Latino-americana/RIBLA. vol. 38. Petrópolis: Vozes, 2001.

GARCÍA, Gabriela Miranda. Las mujeres en la Biblia como referentes simbólicos. Signos de vida. n. 60. Consulta Continental para la VI Asamblea del CLAI. Quito/ Equador: CLAI, 2011, p. 60-63.

GEBARA, Ivone. Sentir o corpo alheio: primeiro grito. In: Um grito pela Vida, Irmã Eurides Alves de Oliveira (Org.). Brasília DF: CRB Nacional, 2013, p. 27-35.

GEBARA, Ivone. Rompendo o silêncio. Uma fenomenologia feminista do mal. Petrópolis, RJ: Vozes, 2000.

GONÇALVES, Alfredo J. Tráfico de pessoas humanas elementos para a prática pastoral. In: Um grito pela Vida. Irmã Eurides Alves de Oliveira (Org.), Brasília DF: CRB Nacional, 2013, p.53-69. 
LOPES, Mercedes. A mulher sábia e a sabedoria mulher. São Leopoldo: OIKOS, 2007.

O' BRIEN, M. A natureza do monoteísmo bíblico: experiência e ideologia”. Concilium, 289. Petrópolis: Vozes, 2001, p.69-77.

MARTINEZ, Raquel Carmen Riquelme. Rompendo as velhas mortalhas: a violência contra a mulher e sua relação com o imaginário androcêntrico de "Deus" na Igreja Metodista do Chile. Revista Mandrágora, ${ }^{\circ}$ 9. Gênero e Religião um caleidoscópio de reflexões. São Bernardo do Campo: UMESP, 2003.

SAMPAIO, Tânia Mara Vieira. Horizontes en discusión en el arte de hacer teología. Revista Alternativas. Manágua: Lascasiana, ano 10, nº 26, julho-dezembro de 2003.

SCHÜSSLER FIORENZA, Elisabeth. Caminhos da Sabedoria - Uma introdução à interpretação bíblica feminista. São Bernardo: Nhanduti Editora, 2009.

SCHÜSSLER FIORENZA, Elisabeth. But She Said: Feminist Practices of Biblical Interpretation. Boston: Beacon Press, 1992. In: Deus (G*d)* trabalha em meio a nós. De uma Política de Identidade para uma Política de Luta. Disponível em: http://www.pucsp.br/rever/rv1_2002/p_fioren. Acesso em: 15.12.2013.

SCHÜSSLER FIORENZA, Elisabeth. As origens cristãs a partir da mulher. Uma nova hermenêutica. São Paulo: Paulinas, 1992.

SEBASTIANI, Lilia. Maria Madalena de personagem do Evangelho a mito de pecadora redimida. Petrópolis: Vozes, 1995.

Recebido: $23 / 08 / 2013$

Received: 08/23/2013

Aprovado: 19/12/2013

Approved: 12/19/2013 